\title{
An infant with Beals- Hecht syndrome: An airway challenge for the anaesthesiologist
}

\author{
Farah Nasreen $^{1^{*}}$, Atif Khalid ${ }^{2}$ \\ Assistant Professor ${ }^{1 *}$, Junior Resident ${ }^{2}$ \\ Department of Anaesthesiology and Critical Care, \\ Jawaharlal Nehru Medical College, Aligarh Muslim University, Uttar Pradesh, India.
}

\begin{abstract}
Beals-Hecht syndrome is a rare connective tissue disorder. Due to multiple contractures, it is associated with difficult airway and other anaesthesia related problems. We hereby present a case of a 2 month old infant who was scheduled for surgical repair of a large inguinal hernia. In view of the anticipated difficult airway, owing to the presence of micrognathia, limited mandibular excursion and cleft palate in this patient, we induced the child with sevoflurane maintaining spontaneous breathing and successfully intubated the child using video laryngoscope (Medicam paediatric video laryngoscope) with Miller blade size 0 . Intraoperative course was uneventful, and the child was extubated at the end of surgery.
\end{abstract}

Keywords: Beals- Hecht syndrome; airway management; video laryngoscope

\section{Introduction}

Beals-Hecht syndrome (congenital contractural arachnodactyly) is a rare autosomal dominantly inherited single gene disorder caused due to mutation in fibrillin 2 gene (FBN2) in chromosome $5 \mathrm{q} 23$, affecting connective tissue. Multiple joint contractures (especially elbow, knee and finger joints), crumpled ears and the absence of aortic root dilatation are the characteristic features of Beal's syndrome that differ it from Marfan syndrome. Craniofacial features include abnormally shaped ears, mild micrognathia and a high arched palate. ${ }^{1}$ Airway management can be challenging in such patients owing to craniofacial anomalies. We present here successful intubation using video laryngoscope in an anticipated difficult airway in a 2 month old infant with Beals syndrome

\section{Case History}

A 2 month old, $2 \mathrm{~kg}$ male infant presented to our hospital with swelling in right inguinal region since birth. Baby was born full term as a normal delivery in a Government hospital. He had an inguinal swelling on the right side of approximately $4 \times 4 \mathrm{~cm}$ in size which increased in size over time to $7 \times 6 \mathrm{~cm}$ at the

*Correspondence: Farah Nasreen

E mail: kazmifarah@gmail.com

https://orcid.org/0000-0001-9796-7303

Received: 22/11/2019

Accepted: 29/03/2020

DOI: http:/doi.org/10.4038/slja.v28i2.8518

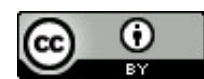

time of presentation to hospital. The shape of the swelling was globular with no redness or discharge and got aggravated on crying or coughing. Since the child also presented with bilateral CTEV, bilateral elbow contracture, scoliosis, micrognathia, limited mandibular excursion and cleft palate, further thorough clinical and radiological examination was done in our hospital and the neonate was suspected to be a case of Beals syndrome which was confirmed on further genetic workup.

Laboratory investigations including systemic and haematological examinations were within normal limits. On airway examination, it was found to have a cleft palate, micrognathia, restricted mouth opening and neck contracture. (Figure 1) These findings suggested an anticipated difficult intubation of the infant and difficult airway cart and preparation for surgical tracheostomy was kept ready.

After fasting for 4 hours for breast milk, the infant was shifted to operation theatre. Monitors including pulse oximeter, electrocardiography, temperature, $\mathrm{ETCO}_{2}$ and non-invasive blood pressure were attached. Premedication was done with atropine $0.02 \mathrm{mg} / \mathrm{kg}$ and fentanyl $2 \mu \mathrm{g} / \mathrm{kg}$ through a $26 \mathrm{G}$ intravenous cannula. General anaesthesia was induced with $8 \%$ sevoflurane in 50:50 oxygen and nitrous oxide. Since the intubation was already anticipated as a difficult one, we used Medicam video laryngoscope Miller 0 blade as the device of choice. Shoulder roll was placed to optimize position and continued oxygenation was done with nasal prongs. Cormack Lehane grade $2 \mathrm{a}$ (Figure 2) was seen on the screen of video laryngoscope after external laryngeal manipulation 


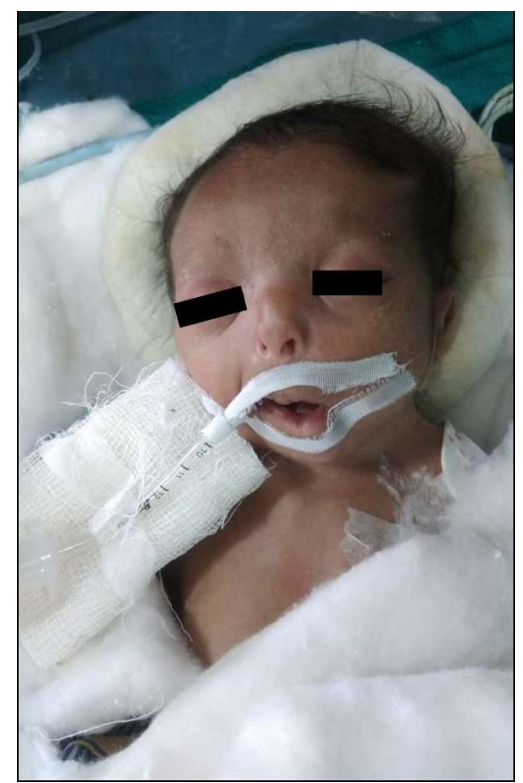

Figure 1: Infant with retrognathia, limited mandibular excursion and cleft palate post intubation.

and an uncuffed size $3.0 \mathrm{~mm}$ tube was inserted on the first attempt with the aid of a stylet. The placement of tube in the trachea was confirmed by $\mathrm{ETCO}_{2}$ monitoring and chest auscultation. Before start of surgery, US guided Transversus abdominis plane block was given with $0.5 \mathrm{ml} / \mathrm{kg}$ of $0.375 \%$ ropivacaine to supplement intraoperative and postoperative analgesia. Intraoperative period was uneventful and successful extubation was done at the end of surgery when the child was fully awake, and reflexes were satisfactory.

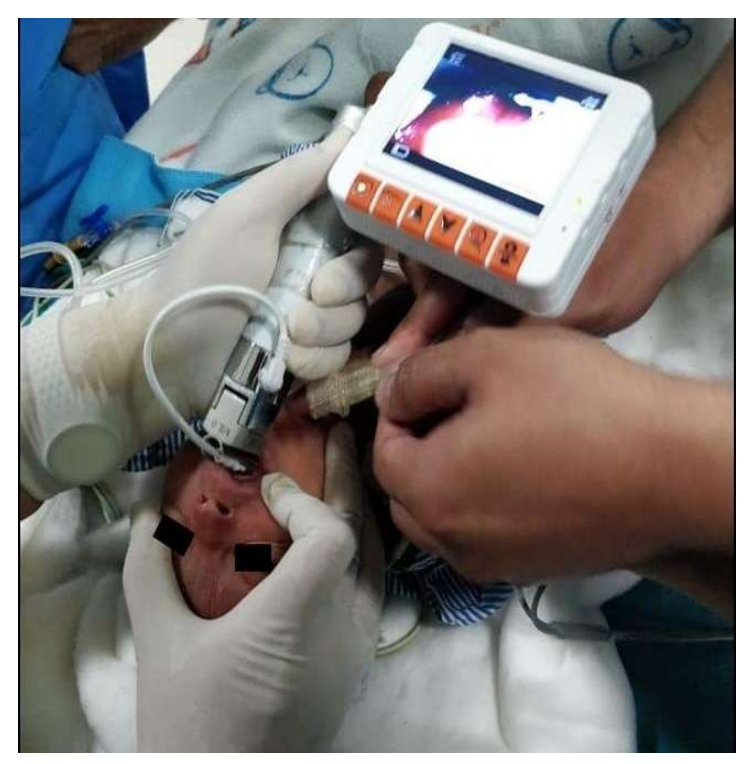

Figure 2: Medicam video laryngoscopy showing Cormack Lehane grade $2 \mathrm{a}$

\section{Discussion}

Beals-Hechts syndrome or Congenital Contractural Arachnodactyly (CCA) is a rare connective tissue disorder and classified as distal arthrogryposis Type 9. ${ }^{2}$ The incidence of CCA is unknown and difficult to estimate due to its phenotypic overlap with Marfan syndrome (MFS), as the clinical distinction is difficult in these two related disorders. ${ }^{3}$ Due to multiple contractures, it is associated with difficult intravenous access, difficult airway and difficult positioning. Scoliosis, kyphosis and thoracic cage abnormalities may lead to severe restrictive lung disease. Other anomalies include cardiac defects, multiple joint contractures, arachnodactyly, kyphoscoliosis, limited mandible excursion and restricted mouth opening. Presence of an abnormal ligament which stretches from maxilla to the mandible anterior to masseter muscles may lead to restricted mouth opening in Beals syndrome. ${ }^{4}$ Due to the presence of associated oral anomalies, airway management can be challenging in such cases. A search into literature revealed a few case reports describing the airway management in older children with Beals syndrome. Amar PB et al reported the use of tracheal tube introducer through laryngeal mask airway as a complex technique for tracheal intubation in a 4-year-old, $15-\mathrm{kg}$ female child with Hecht-Beals syndrome. ${ }^{5}$ In another case report, i-gel LMA was used as a conduit for intubation in a child with Beals syndrome with an unanticipated difficult airway, undergoing emergency surgery. ${ }^{6}$ However, to the best of our knowledge, airway management of an infant with Beals syndrome has not been reported yet. Fiber-optic laryngoscopy guided intubation is the gold standard approach to manage any difficult airway. Non availability of neonatal version of the fiber-optic scope in our setup and vast experience of the anaesthesiologist with the use of paediatric video laryngoscope prompted us to use paediatric video laryngoscope as the first-choice device. Video laryngoscopes have an established role in the management of difficult airway. Current research also supports obvious advantage of video laryngoscope over conventional direct laryngoscopy in paediatric difficult airway. ${ }^{7,8}$ We emphasize on early use of video laryngoscope in such scenario rather than a rescue or a second-choice device as margin of error with intubation is very narrow in neonates and infants. Moreover, repeated attempts with direct laryngoscopy may result in catastrophic results. A video laryngoscope provides a magnified superior glottic view as compared with conventional laryngoscopy. In addition, it is an easy to acquire skill, is intuitive, takes lesser time and allows the assistant to provide correct airway manipulation. ${ }^{9}$ Neonates and infants have a higher incidence of airway related complications than older children and this problem is further compounded 
in a syndromic infant. LMA has been used as a conduit for tracheal intubation by blindly passing a tracheal tube exchanger through it and then railroading endotracheal tube over it in a child with Beals syndrome. ${ }^{5}$ In our case, presence of large cleft, micrognathia and limited mandibular excursion precluded the use of supraglottic airway device (SAD). Moreover, recent guidelines recommend the use of fibreoptic guided intubation through SAD and thus blind insertion of tracheal tube through SAD is imprudent. In view of the anticipated difficult airway, preparation for surgical tracheostomy was kept ready and spontaneous ventilation was preserved using sevoflurane induction till the infant was intubated. In order to optimize position, we put a roll under the shoulder and external laryngeal manipulation was done to optimize laryngeal view on the monitor. In addition, nasal oxygenation was administered with nasal prongs during attempt at laryngoscopy and intubation for apnoeic ventilation which is a recommended technique during difficult paediatric airway management. ${ }^{10}$

There is paucity of literature regarding airway management in infants with Beals syndrome. When dealing with syndromic paediatric patients, expertise with the advanced airway device and its availability is of paramount importance. We highlight the efficacy of paediatric video laryngoscope as the promising first choice device in such vulnerable patients.

\section{References}

1. Gupta B. Congenital contractural arachnodactyly (Beals syndrome): First case report with hypospadias. Indian Paediatrics 2002; 39(12): 1159- 61.

2. Beals R. The distal arthrogryposis: a new classification of peripheral contractures. Clin OrthopRelat Res. 2005; 435:203-10.

https://doi.org/10.1097/01.blo.0000157540.75191.1d

3. Mehar V, Yadav D, Kumar R et al. Congenital contractural arachnodactyly due to a novel splice site mutation in the FBN2 gene. J Pediatr Genet 2014; 3(3):163-6.

https://doi.org/10.3233/PGE-14093

PMid:27625873 PMCid:PMC5020994

4. Mercuri LG. The Hecht, Beals and Wilson syndrome: report of case. J Oral Surgery. 1981;39: 53-56.

5. Kumar A, Chandran R, Khanna P, Bhalla AP. Successful difficult airway management in a child with Hecht-Beals syndrome. Indian J Anaesth 2012;56:5912. https://doi.org/10.4103/0019-5049.104591 PMid:23325953 PMCid:PMC3546255

6. Kalra S. Unanticipated difficult intubation in a child with Beals-Hecht syndrome presenting for emergency surgery. Sri Lankan Journal of Anaesthesiology 2015;23:27-8.

https://doi.org/10.4038/slja.v23i1.7326
7. Xue FS, Tian M, Liao X, Xu YC. Safe and successful intubation using a Storz video laryngoscope in management of pediatric difficult airways. PaediatrAnaesth 2008;18:1251-2. https://doi.org/10.1111/j.1460-9592.2008.02753.x PMid:18717791

8. Diana Raj, Igor Luginbuehl. Managing the difficult airway in the syndromic child. Continuing Education in Anaesthesia Critical Care \& Pain 2015;15( 1)7-13. https://doi.org/10.1093/bjaceaccp/mku004

9. Hooda B, Pandia MP. Pediatric difficult airway. Video laryngoscope to the rescue. J Anaesthesiol Clin Pharmacol 2014;30(4):573-4. https://doi.org/10.4103/0970-9185.142872 PMid:25425791 PMCid:PMC4234802

10. Pawar DK, Doctor JR, Raveendra US, Ramesh S et al. All India Difficult airway association 2016 guidelines for the management of unanticipated difficult tracheal intubation in paediatrics. Indian $\mathrm{J}$ Anaesth 2016;60(12):906-14.

https://doi.org/10.4103/0019-5049.195483

PMid:28003692 PMCid:PMC5168893 